\title{
Hepatitis A Virus and Hepatitis E Virus Seroprevalence Among Blood Donors in Tehran, Iran
}

\author{
Khashayar Hesamizadeh, ${ }^{1,2}$ Heidar Sharafi, ${ }^{1,3}$ Hossein Keyvani, ${ }^{2}$ Seyed Moayed Alavian, ${ }^{1,3}$ \\ Azar Najafi-Tireh Shabankareh, ${ }^{4}$ Roghiyeh Sharifi Olyaie, ${ }^{5}$ and Maryam Keshvari ${ }^{3,5,{ }^{*}}$ \\ ${ }_{1}^{1}$ Baqiyatallah Research Center for Gastroenterology and Liver Diseases, Baqiyatallah University of Medical Sciences, Tehran, IR Iran \\ ${ }^{2}$ Department of Medical Virology, Iran University of Medical Sciences, Tehran, IR Iran \\ ${ }^{3}$ Middle East Liver Disease (MELD) Center, Tehran, IR Iran \\ ${ }_{5}^{4}$ Department of Medical Nanotechnology, School of Advanced Technologies in Medicine, Tehran University of Medical Sciences, Tehran, IR Iran \\ 5 Blood Transfusion Research Center, High Institute for Research and Education in Transfusion Medicine, Tehran, IR Iran \\ *Corresponding Author: Maryam Keshvari, Blood Transfusion Organization Research Center, Tehran, IR Iran. Tel: +98-218860150130, Fax: +98-2166900386, E-mail: m.keshvari@ibto.ir
}

Received 2015 August 8; Revised 2015 November 8; Accepted 2015 November 8.

\begin{abstract}
Background: Hepatitis A virus (HAV) and Hepatitis E virus (HEV) are both transmitted by the fecal-oral route and are known as the leading causes of acute viral hepatitis in the world, especially in developing countries. There is a lack of updated data on HAV and HEV seroprevalence in Iran.

Objectives: The aim of this study was to determine the seroprevalence of HAV and HEV among a group of blood donors in Tehran, Iran. Materials and Methods: A cross-sectional study was performed from July 2014 to December 2014, on a total of 559 blood donors referred to the Tehran blood transfusion center. The serum samples were tested for antibodies to HAV and HEV, using the enzyme-linked immunosorbent assay.

Results: In the present study, 536 (95.9\%) cases were male and 23(4.1\%) female with mean age of 38 years. Out of 559 blood donors,107 (19.1\%) were first-time donors, 163 (29.2\%) lapsed donors and 289 (51.7\%) regular donors. Anti-HAV was found in 395 (70.7\%) and anti-HEV in 45 (8.1\%) of the blood donors. The HAV and HEV seroprevalence increased by age. There was no significant difference between genders in terms of anti-HAV and anti-HEV status. The HAV and HEV seroprevalence was significantly related to the level of education, where the donors with higher level of education had lower rate of HAV and HEV seroprevalence. The HAV and HEV seroprevalence was significantly higher in regular and lapsed donors than in first-time donors.

Conclusions: The present study showed that both HAV and HEV infections are still endemic in Iran.
\end{abstract}

Keywords: Hepatitis A Virus, Hepatitis E Virus, Blood Donors, Prevalence, Iran

\section{Background}

Hepatitis A Virus (HAV) and Hepatitis E Virus (HEV) are the leading causes of acute viral hepatitis worldwide (1). Although these viruses spread by the fecal-oral route or through contaminated water, HEV can be transmitted through animals to humans from exposure to infectious body fluids of infected animals, transfusion of infected blood products, and vertical (maternal-fetal) transmission (2-5). Some epidemics of HAV infection have been described in hemophilic patients, who were treated with factor VIII and IX concentrates and in cancerous cases, who were treated with chemotactic factors like interleukin-2 (6, 7). Nowadays, following the use of treated or synthetic clotting factors, risk of HAV transfusion transmission is scares. In many developing countries, incidence and prevalence of these infections are very closely associated with poor socioeconomic and sanitation level (8). Nevertheless, sporadic infections and outbreaks have been reported in developed countries, which mostly were associated with travel to endemic and epidemic settings like tropical and subtropical areas $(9,10)$. Hepatitis A leads to acute liver disease and often occurs early in life. The clinical range of hepatitis $A$ is variable from asymptomatic infection to rarely fulminant hepatitis. Globally, around 1.5 million symptomatic cases occur each year (11). Hepatitis E occasionally develops into an acute and severe liver disease and is fatal in about $2 \%$ of all cases. Most of HEV infections are acquired in late childhood or young adulthood (8). Transfusion-transmitted HEV infection has been previously reported in some industrialized countries. Caution should be taken in high-risk groups like pregnant women, children, immunocompromised and transplanted recipients, where HEV infection may lead to hazardous transfusion-associated liver disease (12-15). The current study was designed to evaluate the HAV and HEV seroprevalence in blood donors of the Tehran city of Iran from July 2014 to December 2014.

The seroprevalence of HAV and HEV in Iran has been evaluated by some studies. On the other hand, most of the studies on seroprevalence of these viruses focused

Copyright (C) 2016, Kowsar Corp. This is an open-access article distributed under the terms of the Creative Commons Attribution-NonCommercial 4.0 International License (http://creativecommons.org/licenses/by-nc/4.0/) which permits copy and redistribute the material just in noncommercial usages, provided the original work is properly cited. 
on patients with chronic liver diseases $(16,17)$, while community-based studies regarding HAV and HEV seroprevalence are limited in Iran.

\section{Objectives}

The main purpose of the current study was to evaluate the overall immune status of blood donors against HAV and HEV infections in Tehran.

\section{Materials and Methods}

\subsection{Study Population}

This cross-sectional study was carried out on volunteer blood donors, who were referred to donation sites of Tehran blood transfusion center from July to December of 2014. Tehran Blood Transfusion Center is the largest blood bank in Iran and is located in Tehran, with 38 fixed and 1849 mobile donation sites in the Tehran province and with approximately 360,000 donations, annually. The Tehran province is located in the north of Iran with a population of 12183391 (from the last census in 2011). Tehran city is the capital of the province and of Iran. In the $20^{\text {th }}$ and $21^{\text {st }}$ centuries, Tehran has been the subject of mass migration of people from all around Iran. In this study, a regular donor was defined as an individual who donated more than once during a year, lapsed donor was any donor who had a history of previous donation yet the interval between the two donations was more than one year, and first-time blood donor was a donor who donated for the first-time. All donor samples had negative results for hepatitis B surface antigen (HBsAg), anti-hepatitis C virus antibodies (anti-HCV), anti-human immunodeficiency virus type 1 and 2 antibodies (anti-HIV), and syphilis seromarkers. None of the donors had a history of HAV vaccination. All blood donors were interviewed by trained physicians at the blood donation centers, and a questionnaire regarding the viral hepatitis risk factors were filled for each case. The demographic data including age, gender, occupation, donation status and educational level was collected from the Tehran blood transfusion database. A total of 1-2 mL serum for each donor was collected. Collected sera were stored at $-20^{\circ} \mathrm{C}$ until further analysis.

\subsection{Laboratory Assessments}

Detection of anti-HAV IgG and anti-HEV IgG antibodies in the serum was performed using commercial enzymelinked immunosorbent assay kits (DIAPRO, Diagnostic Bioprobes, Milano, Italy), according to the manufacturer's instructions.

\subsection{Statistical Analysis}

Donors' characteristics were expressed by frequencies and percentages. Fisher-exact test, $\chi^{2}$ and one-way analysis of variance (ANOVA) were used for analysis of variables. P values of less than 0.05 were considered statisti- cally significant. Statistical analysis was performed using the SPSS software version 16 and statistical graphs were generated using the Graph Pad Prism version 6.

\section{Results}

Table 1 summarizes the demographic characteristics of the enrolled blood donors $(n=559)$. The majority of the studied participants were male. About $50 \%$ of these participants were aged 18 - 37 years and $43 \%$ were holders of a university degree. In the present study, the mean \pm standard deviation (SD) of age for the first-time donors was $34.2 \pm 10.4$, lapsed donors was $37.2 \pm 9.9$ and regular donors was 39.9 \pm 10.0 ( $\mathrm{P}$ One way-ANOVA $<0.001$ ). The overall prevalence of anti-HAV among our study participants was $70.7 \%$. The rate of anti-HAV seropositivity within age groups, 18 - 27, 28 - 37, 38 - 47 and more than 47 years, increased gradually (26.7\% in the youngest age group to $94.8 \%$ in the oldest age group) (Figure 1). Sixteen (69.6\%) female blood donors were tested positive for anti-HAV and 379 (70.7\%) of male blood donors were seropositive for anti-HAV ( $\mathrm{P}>0.05)$. Overall, 45 (8.1\%) blood samples were positive for anti-HEV, where 43 (8.0\%) samples were from males and two (8.7\%) from females. There was no significant difference in HEV seropositivity by donors' gen$\operatorname{der}(\mathrm{P}=0.7)$. Although the rate of anti-HEV detection was not significantly different between the 18 - 27 and 28 - 37 age groups, anti-HEV was detected more frequently in the 38 - 47 age group and the rate of detection was the highest in the $>47$ age group. On the other hand, about $50 \%$ of HEV seropositive donors were in the $>47$ age group. The HAV and HEV seroprevalence was significantly different regarding the level of education $(\mathrm{P}<0.05)$ with the lowest HAV and HEV prevalence found in university degree holders. Furthermore, donation status impacted HAV and HEV seroprevalence where regular donors had the highest HAV and HEV seroprevalence. In HAV-seropositive donors, 10.1\% were positive for HEV serology, while, 3.0\% of HAV-seronegative donors were HEV-seropositive ( $\mathrm{P}=$ 0.004). Co-seropositivity of HAV and HEV was observed in $40(7.2 \%)$ participants. It should be mentioned that all of the co-seropositive cases were male, however the difference was not statistically significant $(\mathrm{P}>0.05)$.

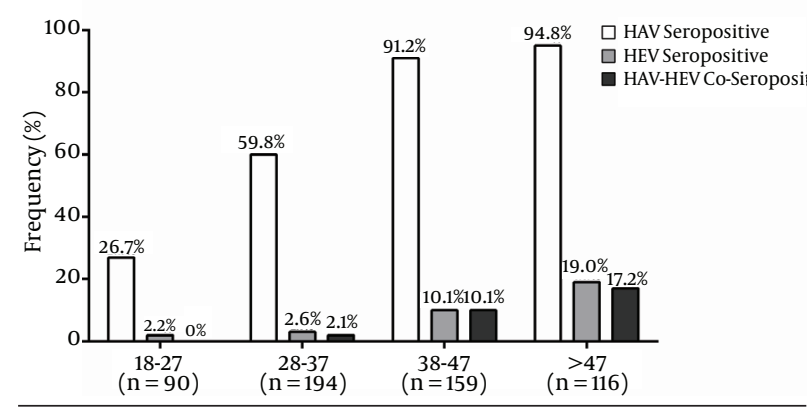

Figure 1. Age-Specific Seroprevalence of Hepatitis A Virus and Hepatitis E Virus Among Blood Donors 
Hesamizadeh Ket al.

Table 1. Seropositivity of Hepatitis A Virus and Hepatitis E Virus in Relation to the Blood Donors' Characteristics

\begin{tabular}{|c|c|c|c|c|c|c|c|}
\hline & \multirow[b]{2}{*}{ All $(\mathbf{n}=559)$} & \multicolumn{2}{|c|}{ HAV } & \multicolumn{4}{|c|}{ HEV } \\
\hline & & $\begin{array}{c}\text { Seronegative } \\
(\mathrm{n}=164)\end{array}$ & $\begin{array}{c}\text { Seropositive } \\
(\mathbf{n}=395)\end{array}$ & PValue & $\begin{array}{l}\text { Seronegative } \\
\quad(n=514)\end{array}$ & $\begin{array}{l}\text { Seropositive } \\
\quad(n=45)\end{array}$ & P Value \\
\hline Gender & & & & $>0.999^{\mathrm{a}}$ & & & $0.707^{\mathrm{a}}$ \\
\hline Male & $536(95.9)$ & $157(95.7)$ & $379(95.9)$ & & $493(95.9)$ & $43(95.6)$ & \\
\hline Female & $23(4.1)$ & $7(4.3)$ & $16(4.1)$ & & $21(4.1)$ & $2(4.4)$ & \\
\hline Educational level & & & & $<0.001^{\mathrm{b}}$ & & & $<0.001^{\mathrm{b}}$ \\
\hline $\begin{array}{l}\text { Less than high school } \\
\text { diploma }\end{array}$ & $103(18.4)$ & $12(7.3)$ & $91(23.0)$ & & $85(16.5)$ & $18(40.0)$ & \\
\hline High school diploma & $215(38.5)$ & $67(40.9)$ & $148(37.5)$ & & $201(39.1)$ & $14(31.1)$ & \\
\hline University level & $241(43.1)$ & $85(51.8)$ & $156(39.5)$ & & $228(44.4)$ & $13(28.9)$ & \\
\hline Donation status & & & & $0.019^{\mathrm{b}}$ & & & $0.043^{b}$ \\
\hline First-time & $107(19.1)$ & $42(25.6)$ & $65(16.5)$ & & $103(20.0)$ & $4(8.9)$ & \\
\hline Lapsed & $163(29.2)$ & $50(30.5)$ & $113(28.6)$ & & $153(29.8)$ & $10(22.2)$ & \\
\hline Regular & 289 (51.7) & $72(43.9)$ & $217(54.9)$ & & $258(50.2)$ & $31(68.9)$ & \\
\hline
\end{tabular}

${ }^{a}$ Fisher exact test.

$\mathrm{b}^{2}$ test.

\section{Discussion}

Scares data is available regarding the seroprevalence of HAV and HEV among Iranian blood donors. Investigation of the HAV and HEV seroprevalence has often been conducted on the blood donor population because of convenience and access to a large sample size. They are generally considered a healthier segment of the community and have been used as a surrogate study population for the prevalence of infections in the community. On the other hand, first-time blood donors have more similarity regarding infectious diseases prevalence to the general population. Iran is located in an endemic region for both HAV and HEV infections, according to centers for disease control and prevention (CDC) data $(18,19)$. This study found that about $70 \%$ of donors in Tehran were HAV-seropositive. Previous studies among Iranian blood donors showed $86 \%$ and 94.9\% of HAV seropositivity in Tehran and Qazvin provinces $(20,21)$. The current study showed that $8 \%$ of Tehran blood donors were positive for anti-HEV. Previous studies reported different HEV seroprevalence among Iranian blood donors. Studies among blood donors from Tehran, West Azarbaijan (Northwest Iran), Khuzestan (Southwest Iran) and Markazi (Center of Iran) provinces showed 7.7\%, $7.8 \%, 11.5 \%$ and $14.3 \%$ for HEV seropositivity, respectively (11, 22-24). There are a few studies on HAV seroprevalence in the general population of Iran. In 2006, a multicenter study by Merat et al. (25) showed that the seroprevalence of HAV was $85 \%, 96 \%$ and $99 \%$ in Tehran, Hormozgan and Golestan provinces, respectively. Another study on 1018 children (six months to 14.9 years) referred to Tehran pediatrics hospitals in 2002 showed 22.3\% HAV seropositivity. The seroprevalence did not differ significantly between males and females and for different age groups (26). Taghavi et al. (27) reported anti-HAV seropositivity of $88.2 \%$ among the adult population in Fars province(Southern Iran) between 2008 and 2009. Another population-based study in 2011 from Tehran found that the overall seroprevalence of anti-HEV and anti-HAV were 9.3\% and 90\%, respectively (28). The present study found that HAV seroprevalence increased by age, on the other hand only $26.7 \%$ of donors in the 18 -27 age group were HAV-seropositive. Moreover, age specific seroprevalence of hepatitis A in Sari, northern Iran, revealed that $39 \%$ of 1 - 25 year-old subjects were seropositive for HAV-IgG in 2007. The authors declared that seroprevalence significantly increased with age (29). A study among a group of patients with chronic liver disease in Jahrom City of Iran showed HAV seroprevalence of 79.2\%; patients aged 20-30 years had the lowest (28.3\%) anti-HAV seropositivity and those aged $>50$ years had the highest (95\%) rate of seropositivity (30). A meta-analysis in Iran found that HAV seroprevalence increased significantly with age where $32 \%$ and $67 \%$ of individuals under 20 and more than 30 years of age were HAV-seropositive, respectively (31). A study among a group of hemophilia and thalassemia patients with HCV infection showed $74.9 \%$ and $2.7 \%$ for HAV and HEV seropositivity (32). Ultimately, low HAV seroprevalence among the young-aged group of donors in this study may be a result of improved social sanitary conditions and access to improved water sources during the recent years. Two studies from Turkey showed a marked decrease in the prevalence of anti-HAV as well $(33,34)$. A significant decrease in the seroprevalence of HAV was reported in 2008 (18.6\%) among Saudi children and adolescents as compared to $52 \%$ and 
25\% reported in 1989 and 1997, respectively (35). A study from Yemen showed an overall seroprevalence of $86.6 \%$ for HAV seropositivity (36).

Previous studies regarding HEV prevalence in the general population of Iran showed different results. A study conducted in 2006, reported $7.4 \%$ for HEV seropositivity in Tehran and Golestan provinces (37). Another study from Golestan found HEV seropositivity of $11.8 \%$ (38). Saffar et al. (39) found HEV seropositivity of $2.3 \%$ in randomly selected apparently healthy 2 - 25 year-olds from urban and rural regions of the Sari district, North of Iran. Another population-based study from Nahavand city, western Iran, found HEV seroprevalence of 9.3\% among individuals aged more than six years in 2003 (40). The author clearly declared that HEV infection is at intermediate prevalence in Nahavand city. Anti-HEV IgG was detected in $18.7 \%$ of blood donors in Mecca, Saudi Arabia (41). A population-based study from Yemen found anti-HEV in $10.7 \%$ of participants; ranging between $0 \%$ in infants to $15.3 \%$ among individuals $>18$ years old (36). A study from Egypt found HEV seropositivity of $46.7 \%$ among pregnant women; this rate was significantly higher in rural areas than in urban areas (78.58\% vs. $21.42 \%$ ) (42). These findings showed that the prevalence of HEV antibodies in our study is less than most countries in the Middle East. Recent studies, with sensitive assays from the United States, southwest England, Germany, Denmark, Netherlands and the southwest of France among blood donors showed $16 \%, 17 \%, 21 \%, 27 \%$ and $52 \%$ for HEV seroprevalence, respectively (43). In the present study, the rate of HEV seropositivity increased with age. This finding was obtained by similar studies $(28,44,45)$.

We found that $7.2 \%$ of subjects were seropositive for both HAV and HEV. Similar results were found in the study of Mohebbi et al. (28). It seems that similar routes for transmission of HEV and HAV, such as using drinking water from wells or streams, which are not treated and probably polluted, and living in areas with improper sanitary conditions, might facilitate this phenomenon. Although Iran is still considered an endemic region for HAV infection, its prevalence has decreased in the recent years. On the other hand, according to the results of the current study, more than $70 \%$ of young donors ( $<27$ years old) were HAV-seronegative. This may be the result of improvements in human hygiene level, promoted health educational propagation and using preventive strategies for HAV infection. In the current study, the seroprevalence of hepatitis A and hepatitis $\mathrm{E}$ in regular donors was more than lapsed and first-time donors, which can be the result of the fact that regular donors were older than lapsed and first-time donors.

In conclusion, given that HAV infection is often symptomatic in adulthood, vaccination of children can be considered. Based on these findings, we unequivocally revealed that the Iranian people are susceptible to hepatitis A, and ultimately, HAV vaccinations should be offered. Furthermore, evaluation of HAV prevalence in different provinces of Iran seems to be crucial for establishment of preventive measures. Hepatitis E Virus can be transmitted through blood products from asymptomatic donors with low-level viremia. Importantly, with regards to the possible severe consequences of transfusion-associated transmission of HEV, especially in immunocompromised patients, the necessity of screening for HEV RNA needs to be revisited in countries with a high HEV prevalence.

\section{Acknowledgments}

We gratefully acknowledge the help of the Tehran blood transfusion centre (TBTC) staff, We also express our special thanks to Keyvan virology laboratory staff for their helping during our study.

\section{Footnotes}

Author's Contribution:All authors contributed to the final version of the manuscript. Maryam Keshvari, Khashayar Hesamizadeh and Heidar Sharafi designed the study and were responsible for the overall study management. Maryam Keshvari, Khashayar Hesamizadeh, Azar Najafi-Tireh Shabankareh and Roghiyeh Sharifi Olyaie organized the analysis. Maryam Keshvari, Khashayar Hesamizadeh, Hossein Keyvani and Seyed Moayed Alavian prepared the manuscript.

Funding/Support:This research was supported by a grant from Baqiyatallah research center for gastroenterology and liver diseases, Baqiyatallah University of Medical Sciences, Tehran, IR Iran.

\section{References}

1. Bernal W, Smith HM, Williams R. A community prevalence study of antibodies to hepatitis A and E in inner-city London. J Med Virol. 1996;49(3):230-4. doi: 10.1002/(SICI)1096 9071(199607)49:3<230::AID-JMV12>3.0.CO;2-G. [PubMed: 8818970]

2. Jacobsen $\mathrm{KH}$, Wiersma ST. Hepatitis A virus seroprevalence by age and world region, 1990 and 2005. Vaccine. 2010;28(41):66537. doi: 10.1016/j.vaccine.2010.08.037. [PubMed: 20723630]

3. Fujiwara S, Yokokawa Y, Morino K, Hayasaka K, Kawabata M, Shimizu T. Chronic hepatitis E: a review of the literature. J Viral Hepat. 2014;21(2):78-89. doi: 10.1111/jvh.12156. [PubMed:24383921]

4. Matsubayashi K, Kang JH, Sakata H, Takahashi K, Shindo M, Kato $\mathrm{M}$, et al. A case of transfusion-transmitted hepatitis E caused by blood from a donor infected with hepatitis $\mathrm{E}$ virus via zoonotic food-borne route. Transfusion. 2008;48(7):1368-75. doi 10.1111/j.1537-2995.2008.01722.x. [PubMed: 18651907]

5. Boxall E, Herborn A, Kochethu G, Pratt G, Adams D, Ijaz S, et al. Transfusion-transmitted hepatitis $\mathrm{E}$ in a 'nonhyperendemic' country. Transfus Med. 2006;16(2):79-83. doi: 10.1111/j.13653148.2006.00652.x. [PubMed:16623913]

6. Soucie JM, Robertson BH, Bell BP, McCaustland KA, Evatt BL. Hepatitis A virus infections associated with clotting factor concentrate in the United States. Transfusion. 1998;38(6):573-9. [PubMed: 9661691]

7. Weisfuse IB, Graham DJ, Will M, Parkinson D, Snydman DR, Atkins $\mathrm{M}$, et al. An outbreak of hepatitis A among cancer patients treated with interleukin-2 and lymphokine-activated killer cells. JInfect Dis. 1990;161(4):647-52. [PubMed:2319165]

8. Favorov MO, Fields HA, Purdy MA, Yashina TL, Aleksandrov AG, Alter MJ, et al.Serologic identification of hepatitis E virus infections in epidemic and endemic settings. J Med Virol.1992;36(4):246-50. [PubMed: 1578218] 
9. WHO. Hepatitis A. Geneva; World Health Organization. 2000

10. WHO. Hepatitis E. Geneva; World Health Organization. 2001.

11. Assarehzadegan MA, Shakerinejad G, Amini A, Rezaee SA. Seroprevalence of hepatitis $\mathrm{E}$ virus in blood donors in Khuzestan Province, southwest Iran. Int J Infect Dis. 2008;12(4):387-90. doi: 10.1016/j.ijid.2007.09.015. [PubMed: 18063401]

12. Matsubayashi K, Nagaoka Y, Sakata H, Sato S, Fukai K, Kato T, et al. Transfusion-transmitted hepatitis E caused by apparently indigenous hepatitis E virus strain in Hokkaido, Japan. Transfusion. 2004;44(6):934-40. doi: 10.1111/j.1537-2995.2004.03300.x. [PubMed: 15157263]

13. Hewitt PE, Ijaz S, Brailsford SR, Brett R, Dicks S, Haywood B, et al. Hepatitis E virus in blood components: a prevalence and transmission study in southeast England. Lancet. 2014;384(9956):176673. doi: 10.1016/S0140-6736(14)61034-5. [PubMed:25078306]

14. Huzly D, Umhau M, Bettinger D, Cathomen T, Emmerich F, Hasselblatt P, et al. Transfusion-transmitted hepatitis E in Germany, 2013. Euro Surveill. 2014;19(21):pii=20812. [PubMed: 24906377]

15. Colson P, Coze C, Gallian P, Henry M, De Micco P, Tamalet C. Transfusion-associated hepatitis E, France. Emerg Infect Dis. 2007;13(4):648-9. doi:10.3201/eid1304.061387. [PubMed:17561564]

16. Somi MH, Farhang S, Majidi G, Shavakhi A, Pouri A. Seroprevalence of hepatitis $\mathrm{E}$ in patients with chronic liver disease from East Azerbaijan, Iran. Hep Mon. 2007;7:125-8.

17. Roushan MR, Bijani A, Sagheb R, Jazayeri O. Prevalence of hepatitis A IgG in individuals with chronic hepatitis B infection in Babol. East Mediterr Health J. 2007;13(5):1108-13. [PubMed: 18290404]

18. CDC. Hepatitis A. Atlanta: Centers for Disease Control and Prevention; 2011. Available from: www.cdc.gov/travel/yellowbook/2012/ chapter-3-infectious-diseases-related-to-travel/hepatitis-a. htm\#2394.

19. CDC. Hepatitis E information for health professionals. Atlanta: Centers for Disease Control and Prevention; 2009. Available from: http://www.cdc.gov/hepatitis/HEV/HEVfaq.htm\#section1.

20. Elikaei A, Sharifi Z, Shooshtari M, Hosseini M, Maroufi Y. Prevalence of HAV among healthy blood donors referring to Tehran transfusion center. Iran J Public Health. 2008;37(4):126-30.

21. Ramezani H, Bozorgi SH, Nooranipour M, Mostajeri A, KargarFard H, Molaverdikhani S, et al. Prevalence and risk factors of hepatitis A among blood donors in Qazvin, central Iran. Singapore Med J. 2011;52(2):107-12. [PubMed: 21373737]

22. Aminiafshar S, Alimagham M, Gachkar L, Yousefi F, Attarchi Z. Anti hepatitis E virus seropositivity in a group of blood donors. Iran JPublic Health. 2004;33(4):53-6.

23. Taremi M, Gachkar L, MahmoudArabi S, Kheradpezhouh M, Khoshbaten M. Prevalence of antibodies to hepatitis E virus among male blood donors in Tabriz, Islamic Republic of Iran. East Mediterr Health J. 2007;13(1):98-102. [PubMed: 17546911]

24. Ehteram H, Ramezani A, Eslamifar A, Sofian M, Banifazl M, Ghassemi S, et al. Seroprevalence of Hepatitis E Virus infection among volunteer blood donors in central province of Iran in 2012. Iran J Microbiol. 2013;5(2):172-6. [PubMed: 23825737]

25. Merat S, Rezvan H, Nouraie M, Abolghasemi H, Jamali R, AminiKafiabad S, et al. Seroprevalence and risk factors of hepatitis A virus infection in Iran: a population based study. Arch Iran Med. 2010;13(2):99-104. [PubMed: 20187662]

26. Mehr AJ, Ardakani MJ, Hedayati M, Shahraz S, Mehr EJ, Zali MR. Age-specific seroprevalence of hepatitis A infection among children visited in pediatric hospitals of Tehran, Iran. Eur J Epidemiol. 2004;19(3):275-8. [PubMed: 15117123]

27. Taghavi SA, Hosseini Asl MK, Talebzadeh M, Eshraghian A. Seroprevalence study of hepatitis A virus in Fars province, southern Iran. Hepat Mon. 2011;11(4):285-8. [PubMed: 22706273]

28. Mohebbi SR, Rostami Nejad M, Tahaei SM, Pourhoseingholi MA, Habibi M, Azimzadeh P, et al. Seroepidemiology of hepatitis $\mathrm{A}$ and $\mathrm{E}$ virus infections in Tehran, Iran: a population based study. Trans R Soc Trop Med Hyg. 2012;106(9):528-31. doi: 10.1016/j. trstmh.2012.05.013. [PubMed: 22835757]

29. Alian S, Ajami A, Ghasemian R, Yadegarinia D. Age-specific seroprevalence of hepatitis A in Sari, northern Islamic Republic of Iran. East Mediterr Health J. 2011;17(10):754-8. [PubMed: 22256409]

30. Ahmadi Vasmehjani A, Javeshghani D, Baharlou R, Shayestehpour M, Mousavinasab SD, Joharinia N, et al. Hepatitis A infection in patients with chronic viral liver disease: a cross-sectional study in Jahrom, Iran. Epidemiol Infect. 2015;143(3):534-9. doi: 10.1017/S0950268814000806. [PubMed: 24742346]

31. Farajzadegan Z, Hoseini SG, Kelishadi R, Jamshidi F, Nokhodian $\mathrm{Z}$, Noori R, et al. Systematic review and meta-analysis on the age-specific seroprevalence of hepatitis A in Iran. J Res Med Sci. 2014;19(Suppl 1):S56-63. [PubMed: 25002897]

32. Karimi Elizee P, Alavian SM, Miri SM, Behnava B, Alavian SH, Keshvari $\mathrm{M}$, et al. The seroprevalence of entrically transmitted viral hepatitis in hcvinfected thalassemia and hemophilia patients in iran.Jundishapur J Microbiol. 2013;6(7):9091.

33. Kurugol Z, Aslan A, Turkoglu E, Koturoglu G. Changing epidemiology of hepatitis A infection in Izmir, Turkey. Vaccine. 2011;29(37):6259-61. doi: 10.1016/j.vaccine.2011.06.069. [PubMed: 21763745]

34. Nalbantoglu B, Donma MM, Ozdilek B, Karasu E, Nalbantoglu A Shifting epidemiology of hepatitis a infection and vaccination status of children aged 6 months-12 years: time for mass vaccination. Iran J Pediatr. 2013;23(3):276-80. [PubMed: 23795249]

35. Melhem NM, Talhouk R, Rachidi H, Ramia S. Hepatitis A virus in the Middle East and North Africa region: a new challenge. J Viral Hepat. 2014;21(9):605-15. doi: 10.1111/jvh.12282. [PubMed: 25040644]

36. Bawazir AA, Hart CA, Sallam TA, Parry CM, Beeching NJ, Cuevas LE. Seroepidemiology of hepatitis A and hepatitis E viruses in Aden, Yemen. Trans R Soc Trop Med Hyg. 2010;104(12):801-5. doi: 10.1016/j. trstmh.2010.08.007. [PubMed: 20828772]

37. Sepanlou S, Rezvan H, Amini-Kafiabad S, Dayhim M, Merat S. A Population-based Seroepidemiological Study on Hepatitis E Virus in Iran. Middle East J Dig Dis. 2010;2(2):97-103. [PubMed: 25197520]

38. Ghadir MR, Jafari E, Rezvan H, Amini KS, JAVADI Vaez M, Pourshams A. Hepatitis A and $\mathrm{E}$ in the east of Golestan province.J Med Council. 2007;25(1):34-8.

39. Saffar MJ, Farhadi R, Ajami A, Khalilian AR, Babamahmodi F, Saffar H. Seroepidemiology of hepatitis E virus infection in 2-25-year-olds in Sari district, Islamic Republic of Iran. East Mediterr Health J. 2009;15(1):136-42. [PubMed:19469436]

40. Taremi M, Mohammad Alizadeh AH, Ardalan A, Ansari S, Zali MR. Seroprevalence of hepatitis E in Nahavand, Islamic Republic of Iran: a population-based study. East Mediterr Health J. 2008;14(1):157-62. [PubMed: 18557463]

41. Johargy AK, Mahomed MF, Khan MM, Kabrah S. Anti hepatitis E virus seropositivity in a group of male blood donors in Makkah, Saudi Arabia.J Pak Med Assoc. 2013;63(2):185-9. [PubMed:23894892]

42. Gad YZ, Mousa N, Shams M, Elewa A. Seroprevalence of subclinical HEV infection in asymptomatic, apparently healthy, pregnant women in Dakahlya Governorate, Egypt. Asian JTransfus Sci. 2011;5(2):136-9. doi: 10.4103/0973-6247.83238. [PubMed: 21897591]

43. Hogema BM, Molier M, Slot E, Zaaijer HL. Past and present of hepatitis E in the Netherlands. Transfusion. 2014;54(12):3092-6. doi: 10.1111/trf.12733. [PubMed: 24889277]

44. Meng XJ, Wiseman B, Elvinger F, Guenette DK, Toth TE, Engle RE, et al. Prevalence of antibodies to hepatitis $E$ virus in veterinarians working with swine and in normal blood donors in the United States and other countries. J Clin Microbiol. 2002;40(1):117-22. [PubMed:11773103]

45. Petrovic T, Lupulovic D, Jimenez de Oya N, Vojvodic S, Blazquez $\mathrm{AB}$, Escribano-Romero E, et al. Prevalence of hepatitis $\mathrm{E}$ virus (HEV) antibodies in Serbian blood donors. J Infect Dev Ctries. 2014;8(10):1322-7. doi:10.3855/jidc.4369. [PubMed: 25313610] 